\title{
Detecting the Incidence and Benefits Foregone of Elder Abuse Neglect: The Case of Hearing Aids in Nursing Homes
}

\author{
Robert J. Brent* \\ Department of Economics, Fordham University, 441 East Fordham Road, Bronx, New York 10458.
}

\begin{abstract}
Neglect is the form of elder abuse that is most likely to be underreported. We provide a three-part test that can be used to uncover the incidence of elder abuse neglect. We apply the test to nursing homes in the form of the under-provision of hearing aids (HAs). To prove HA neglect, it must be shown that they are needed, socially worthwhile and underprovided. All three test results reveal negligence in the context of HAs in nursing homes. The main contribution of the article is to provide empirical evidence related to the third test, based on a large national panel data set using a two-way, random effects regression. Nursing home usage of HAs is one-sixth lower that it would be if older adults lived out in the community. The approximate value lost in the US by this elder abuse neglect is estimated to be $\$ 4.4$ billion. It is recommended that greater use of hearing aids would be forthcoming if the nursing home institutions themselves recognized the nature and scope of the hearing loss problem of residents
\end{abstract}

Keywords: Detecting Elder Abuse Neglect; Nursing Homes; Hearing Aids; Foregone Benefits.

\section{INTRODUCTION}

Elder abuse can be defined as occurring when there is mistreatment to an older adult in the context of a trusting relationship in which the trust of the older victim has been violated. Elder abuse comes in many forms. The five mains ones are physical, sexual, psychological, financial and neglect. In a review of national surveys of the one-year prevalence of all forms of elder abuse by Lachs and Pillemer (2015), they report that Laumann et al. (2018) found a $9 \%$ estimate and Acierno et al. (2010) came up with a $10 \%$ estimate. Lachs and Pillemer also referred to a large New York State study by Lachs and Berman (2011) that estimated the elder abuse rate to be $7.6 \%$. On the basis of these three epidemiological studies of community dwelling older adults, Lachs and Pillemer concluded that an overall prevalence estimate of $10 \%$ for elder abuse would be reasonable. Clearly elder abuse is widespread. With the aging of the population in the US and worldwide, elder abuse can be expected to increase further. The more we understand the nature of elder abuse, the more we can attempt to prevent it or otherwise remedy it. Once quantified, the value of the foregone benefits can be estimated.

In the New York State study, many of the victims experienced more than one form of elder abuse. The incidence rate of financial abuse was 42.1 per 1000 adults over the age of 60 ; the rate was 22.4 for physical and sexual abuse; it was 18.3 for neglect, and 16.4 for psychological (emotional)

*Address correspondence to this author at Department of Economics, Fordham University, 441 East Fordham Road, Bronx, New York 10458;

Tel: 718-817-4058; E-mail: brent@fordham.edu abuse. What was particularly important about these selfreported incidence rates of elder abuse was that they were on average nearly 24 times greater than the officially documented cases that were referred to social service, law enforcement or legal authorities who are responsible for assisting older adult victims. This gross, official under-reporting means that much of the elder abuse remains hidden, what Lachs and Berman call "under the radar". In this article, we will be showing how evidence of elder abuse can be brought more out in the open so that it can be more fully quantified and addressed.

The form of elder abuse that was most under-reported is neglect, where the self-reported rate was 57.2 times as large as the official rate. By its very nature, neglect is particularly hard to measure. It is much easier to observe behavior that causes harm rather than detect actions that fails to do something that is safe or otherwise beneficial. In this article, we are attempting to contribute to the elder abuse literature by suppling a test for the existence of elder abuse in the form of neglect. How to apply the test will be illustrated in the context of a particular health service deprivation, i.e., the caregiver in nursing homes (NHs) not providing hearing aids (HA) to residents with hearing loss (HL). Caregiving at NHs is a clear example of a situation where a trusting relationship exists between the older adult and the caregiver. The result of applying the test is that we will be able to provide an estimate of the extent to which the non-provision of HAs by caregivers in NHs can be considered evidence of elder abuse neglect.

The test has three parts. First, it must be demonstrated that what is not being provided by the caregiver is a need for the older adult. Section II deals with this part of the test. Second, what is needed should be something that is socially worth- 
while. Section III covers this part of the test. And third, what is needed and socially worthwhile has to be shown to be something that has been deprived from the older adult. Carrying out this third part of the test is the main contribution of this article. We carry out an empirical analysis of the reasons why people wear HAs in order to assign responsibility for their non-use to either the older adult or the caregiver in the $\mathrm{NH}$. This analysis takes place in section IV using a large, national set of panel data collected by the National Alzheimer's Coordinating Center (NACC). Section V provides the summary and main conclusions.

\section{ESTABLISHING THE NEED FOR HEARING AIDS}

The most obvious reason why a HA would satisfy the test of being needed is that, on the basis of some sort of hearing exam, the verdict is that a person has a HL that a HA would remedy. In our data set, everyone we will be analyzing has had their hearing evaluated and has been found to have a HL. Therefore, this simple test of need for HAs has been satisfied in our application. However, there is a more general specification for a test of need that can apply to any case of neglect, and not just for HAs, and we will explain this way of checking for need.

According to Lachs and Berman, a responsible caregiver is one who provides the activities of daily living (ADL) of the older person in their charge. Therefore, for the general specification of a test of need, neglect exists when the caregiver does not provide the necessary ADLs. Some ADLs include basic needs (such as eating, bathing, dressing, toileting and walking) and others are higher functional activities that are instrumental in satisfying the basic needs (including shopping, meal preparation, basic housework or taking medicine). The basic need ADL that we will be addressing in this article relates to a higher functional activity, that is, communication, and McCreedy et al. (2018) point out that HL disrupts communication. The instrument that will help to satisfy the communication need is a HA, and neglect occurs when a caregiver does not provide it.

\section{CHECKING THAT HEARING AIDS ARE SOCIAL- LY WORTHWHILE.}

To test whether any ADL is to be judged socially worthwhile, a cost-benefit analysis (CBA) is required. It is worthwhile if the benefits exceed the costs. Benefits are outcomes valued in monetary terms, so that they are in the same units as the monetary costs, which are the values given to the inputs. There are many different ways of valuing the benefits, see for example, Brent (2006, 2014, 2017). Given that most older adults are not employed (though many serve as unpaid volunteers), earnings are not a possible method for valuing the benefits of ADL. More relevant is the quality and quantity of life that results, which together forms what is called a quality adjusted life year, a QALY. When a QALY is the outcome measure, putting a price on the QALY completes the task of valuing the benefits of ADLs.

There are two central principles behind any CBA. One is that the benefits and costs of everyone affected by an ADL must be included. This means that the effects on the older adults must be included and also the effects on the caregivers. When caregivers are out in the community, their services need to be valued separately. However, when caretakers are, as in our application, working in a nursing home, the value of the services they provide can simply be subsumed by their wages and salaries. The second CBA principle is that it is the preferences of all those affected that must be valued. The principle is called "consumer sovereignty" whereby individuals are judged to be the best judge of their own welfare. It was this principle that was invoked to value physical, psychological, and financial elder abuse, by recording whether victims were willing to prosecute their abusers when law enforcement was called in to mediate a dispute (Brent, 2015). In this current article, we honor consumer sovereignty by using as a benchmark, for the "correct" HA usage rate by older adults in NHs, the HA usage in more independent residences.

In the case of HAs, a CBA was carried out as a companion piece to this article (Brent, 2019). This used the same data set that we will be using for the empirical part of this study. The benefits of HAs arose because HAs increased the quality of life of its wearers (from both those with and without dementia) and the value of increasing ones quality of life has been estimated in the literature. The estimate of the benefits of HAs over a person's lifetime came out to be nearly a quarter of a million dollars $(\$ 248,425)$. The lifetime costs of HAs were $\$ 8,498$, which made the net-benefits $\$ 239,927$. With a benefit-cost ratio of nearly 30 , any provision of HAs would clearly increase social welfare.

\section{EVIDENCE OF HA DEPRIVATION.}

HAs have just been shown to be needed and increase social welfare. The final test for evidence of elder abuse neglect is to confirm that HAs actually would have been chosen by older adults if they were outside a NH, so not providing them is actually deprivation by the $\mathrm{NH}$ caregivers.

There is ample evidence that out in the community, and not just in NHs, older adults with HL mostly do not wear HAs. In a population based sample in the US, Fischer et al. (2011) found that close to two-thirds of persons with a HL (and followed over 10 years) did not acquire a HA, despite the fact that actual and perceived hearing worsened over the period. Factors that determined HA acquisition were education, income, HL severity and self-perception of hearing quality, Thus, non-use of HAs does not automatically provide evidence that neglect has been present, because people may choose not to acquire them.

What is missing from the literature is the role of NHs in the non-use of HAs. If non-use were higher in NHs than in residences elsewhere, then neglect would be present (when the other two requirements have been met, as in our study). The main contribution of our study is to fill the gap in the HA usage literature by focusing on an older adult's residential situation. We will be analyzing four types of residential living:

R1: Private residence.

R2: Independent group living.

R3: Assisted living.

R4: Nursing home. 
The objective of the analysis is to determine the extent to which the wearing of HAs by older adults is lower in NHs (R4) than in other types of residential living.

\section{Estimation framework}

The dependent variable is whether a person with HL usually wears a HA, which we refer to as HAW. This is represented by a dummy variable, where HAW $=1$ when the person usually wears the HA, and HAW $=0$ when the person does not usually wear a HA. Because we are going to be using panel data to make our estimation, we express the dependent variable as HAWiv, where i denotes an individual, and $\mathrm{v}$ denotes the visit number that the person makes to an Alzheimer's Disease Center (ADC) where HL is being tested, and the wearing of a $\mathrm{HA}$ is being monitored. ${ }^{1}$

The main independent variable is also a dummy variable. It is the $\mathrm{NH}$ residence variable R4. For the controls, we will use the same set of demographic and socio-economic (X) and health and medical $(\mathrm{H})$ variables that were used to estimate the HAs CBA equations. The binary choice model can be represented by a regression equation, specified in a twoway, random effects context as: ${ }^{2}$

$\mathrm{HAWiv}=\pi 0+\pi 1 \mathrm{R} 4 \mathrm{iv}+\pi 2 \mathrm{Xiv}+\pi 3 \mathrm{Hiv}+\mathrm{ui}+\mathrm{uv}+\mathrm{uiv}$ (1)

where: ui, uv, and uiv are the random error terms (all assumed to be uncorrelated with the independent variables in the equation); and the $\pi$ are the fixed regression coefficients to be estimated. Note that, of the residence variables, only $\mathrm{R} 4$ is included in the regression equation. The regression coefficient $\pi 1$ must be interpreted with R1, R2 and R 3 as the reference cases. That is, $\pi 1$ gives the impact of $\mathrm{NHs}$ on HAW relative to any other type of residence. Because the dependent variable is a dummy variable, Probit is used to carry out the estimation of equation (1), where HAW $=1$ if a person usually wears an HA and HAW $=1$ if the person does not.

\section{The NACC data set}

To estimate equation (1) we will use the NACC data set that was also used for the HA CBA. NACC has constructed a panel data set that has been operational since September 2005, called the Uniform Data Set (UDS). These data consist of demographic, clinical, diagnostic, and neuropsychological information on participants with normal cognition, mild cognitive impairment, and dementia who visited approximately 32 US Alzheimer's Disease Centers (ADC). The UDS is explained elsewhere (Morris et al., 2006, Beekly et al., 2007 and Weintraub et al., 2009). The version used in our analysis, with data through February 2017, covers up to 12 visits over a thirteen-year period and has 107, 692 visits recorded with a HL assessment.

\footnotetext{
${ }^{1}$ Although it is more usual to denote an observation in a panel data set by it, because there is a strong correspondence between visits and time (year) in our data set, we use instead the notation $i v$.

${ }^{2}$ Because of the "incidental parameters problem" with binary dependent variables, Wooldridge (2002), a fixed effects panel data model could not be applied. Therefore, we used the random effects model instead.
}

As the first test for neglect is that a person have a HL, we will only use visit data where HL was confirmed. To see what our sample contains, Table 1 shows the two-way contingency table related to the absolute frequencies for visits by clients with and without normal hearing $(\mathrm{HL}=0$ and $\mathrm{HL}=$ 1) and those who do and do not usually wear a HA (HAW = 1 and HAW $=0$ ).

Table 1: Contingency table relating wearing a hearing aid and having a hearing loss

\begin{tabular}{|c|c|c|c|}
\hline \multicolumn{4}{|c|}{ Wears a Hearing Aid } \\
\hline Need for a Hearing Aid & HAW $=0$ & HAW $=1$ & Total \\
\hline$H L=1$ & 10,702 & 15,838 & 26,540 \\
\hline$H L=0$ & 79,972 & 1,180 & 81,152 \\
\hline & 90,674 & 17,018 & 107,692 \\
\hline
\end{tabular}

As we can see, of the 107,692 visits where hearing was assessed, for $26,540(24.64 \%)$ of the client visits did not have normal hearing $(\mathrm{HL}=1)$; and of these client visits, 10,707 $(40.34 \%)$ took place with clients not wearing HAs $(\mathrm{HA}=0)$ even though they were needed. Unlike the national survey of HA use by Fischer et at al. cited earlier, our sample has over half $(59.4 \%)$ of the persons with HL who did actually wear one.

Our analysis will focus on the 26,540 client visits with HL who decided whether to usually wear a HA, or not. Table 2 states the definitions of all the variables used in the estimation of equation (1). The demographic and socio-economics controls were education, gender, age, race, marital status and being eligible for Medicare. The health and medical controls were, BMI, height, alcohol and cigarette use, heart rate and dementia.

Table 2. Definitions of all the variables.

\begin{tabular}{|l|l|}
\hline \multicolumn{1}{|c|}{ Variable } & \multicolumn{1}{c|}{ Description } \\
\hline HAW: & $\begin{array}{l}\text { Does the subject usually wear a hearing } \\
\text { aid? } \\
1=\text { Yes if the subject wears a hearing aid to } \\
\text { perform everyday activities (such as listen- } \\
\text { ing to the radio or television, talking with } \\
\text { family and friends); 0 = No }\end{array}$ \\
\hline R1: Private Residence & $\begin{array}{l}\text { Single- or multi- family private residence } \\
\text { (apartment, condo, house). }\end{array}$ \\
\hline R2: Independent Group & $\begin{array}{l}\text { Retirement community or independent } \\
\text { group living. }\end{array}$ \\
\hline Living & $\begin{array}{l}\text { Assisted living, adult family home, or } \\
\text { boarding home. }\end{array}$ \\
\hline X1: Ln Education & $\begin{array}{l}\text { Skilled nursing facility, nursing home, } \\
\text { hospital, or hospice. }\end{array}$ \\
\hline Rursing Home (NH) & Subject's years of education in natural logs. \\
\hline Subject's sex: \\
\hline Female = 1; Male = 0.
\end{tabular}




\begin{tabular}{|l|l|}
\hline X3: Age & Subjects age at time of visit. \\
\hline X4: White & $\begin{array}{l}\text { NIH Race definition: White }=1 \text {; Non-white } \\
=0 .\end{array}$ \\
\hline X5: Married & $\begin{array}{l}\text { Subject's marital status is married: } \\
\text { Yes = 1; All other statuses }=0 .\end{array}$ \\
\hline X6: Medicare & $\begin{array}{l}\text { Eligible for Medicare, aged 65 years or } \\
\text { older. }\end{array}$ \\
\hline H1: BMI & $\begin{array}{l}\text { Body Mass Index = weight (lbs) } \times 703 \text { / } \\
\text { height (in) }\end{array}$ \\
\hline H2: Height & Subject's height in inches. \\
\hline H3: Alcohol & $\begin{array}{l}\text { Alcohol abuse clinically significant occur- } \\
\text { ring over a 12-month period: } 1=\text { Absent; 0 } \\
=\text { Not absent. }\end{array}$ \\
\hline H4: Smoking & Total years smoked cigarettes. \\
\hline H5: Heart Rate & Subject resting heart rate (pulse). \\
\hline H6: Dementia & $\begin{array}{l}\text { Clinical Dementia Rating scale }(C D R \circledR \\
\text { dementia staging instrument): Sum of Box- } \\
\text { es (SB). }\end{array}$ \\
\hline V: Visits & \begin{tabular}{l} 
Number of UDS visits at ADCs \\
\hline
\end{tabular} \\
\hline
\end{tabular}

Table 3 gives the data summary. In the sample, $1 \%$ resided in a $\mathrm{NH}, 45 \%$ were female, $88 \%$ were white, $60 \%$ were married and $94 \%$ eligible for Medicare. The average age in the sample was 79 years.

Table 3. Descriptive Statistics for all the Variables.

\begin{tabular}{|c|c|c|c|c|c|}
\hline Variable & Number & Mean & SD & Minimum & Maximum \\
\hline $\begin{array}{c}\text { HAW: Wear a } \\
\text { Hearing Aid }\end{array}$ & 25,619 & 0.60 & 0.49 & 0 & 1 \\
\hline $\begin{array}{l}\text { R1: Private } \\
\text { Residence }\end{array}$ & 25,619 & 0.85 & 0.36 & 0 & 1 \\
\hline $\begin{array}{l}\text { R2: Independent } \\
\text { Group Living }\end{array}$ & 25,619 & 0.11 & 0.31 & 0 & 1 \\
\hline $\begin{array}{l}\text { R3: Assisted } \\
\text { Living }\end{array}$ & 25,619 & 0.03 & 0.18 & 0 & 1 \\
\hline $\begin{array}{l}\text { R4: Nursing } \\
\text { Home }\end{array}$ & 25,619 & 0.01 & 0.10 & 0 & 1 \\
\hline $\begin{array}{l}\text { X1: Ln Educa- } \\
\text { tion }\end{array}$ & 25,619 & 2.71 & 0.27 & 0 & 3.4 \\
\hline X2: Female & 25,619 & 0.45 & 0.50 & 0 & 1 \\
\hline X3: Age & 25,619 & 79.46 & 8.98 & 21 & 107 \\
\hline X4: White & 25,619 & 0.88 & 0.33 & 0 & 1 \\
\hline X5: Married & 25,619 & 0.60 & 0.49 & 0 & 1 \\
\hline
\end{tabular}

\begin{tabular}{|c|c|c|c|c|c|}
\hline X6: Medicare & 25,619 & 0.94 & 0.23 & 0 & 1 \\
\hline H1: BMI & 23,557 & 26.57 & 4.65 & 12.1 & 58.9 \\
\hline H2: Height & 23,884 & 65.80 & 4.10 & 46 & 79 \\
\hline H3: Alcohol & 22,709 & 0.94 & 0.24 & 0 & 1 \\
\hline H4: Smoking & 22,129 & 11.44 & 16.01 & 0 & 82 \\
\hline H5: Heart Rate & 23,710 & 67.51 & 10.78 & 33 & 160 \\
\hline H6: Dementia & 25,619 & 2.59 & 3.91 & 0 & 18 \\
\hline Visits & 25,619 & 3.39 & 2.40 & 1 & 12 \\
\hline
\end{tabular}

\section{Results}

The Probit random effects marginal probabilities are shown in Table 4. Column (1) has the result for NH residence without any controls. Column (2) adds the demographic and socio-economic controls, and column (3) adds the medical and health care controls. In column (3), all variables are significant at least the $1 \%$ level. All six of the demographic and socio-economics variables were significant. Only dementia was significant of the health and medical variables.

Table 4. Probit Random Effects Estimates (Average Marginal Effects) of Nursing Home Residence on Hearing Aid Use (pValues in Parentheses) $\dagger$.

\begin{tabular}{|c|c|c|c|}
\hline Variable & (1) & (2) & (3) \\
\hline $\begin{array}{c}\text { R4: Nursing Home } \\
\pi_{l}\end{array}$ & $\begin{array}{c}-0.4127 * * * \\
(0.000)\end{array}$ & $\begin{array}{c}-0.3327 * * * \\
(0.000)\end{array}$ & $\begin{array}{c}-0.1672 * * * \\
(0.000)\end{array}$ \\
\hline X1: Ln Education & & $\begin{array}{c}0.2712^{* * * *} \\
(0.000)\end{array}$ & $\begin{array}{c}0.1925^{* * * *} \\
(0.000)\end{array}$ \\
\hline X2: Female & & $\begin{array}{c}-0.1415^{* * *} \\
(0.000)\end{array}$ & $\begin{array}{c}-0.1530^{* * *} \\
(0.000)\end{array}$ \\
\hline X3: Age $A: \pi_{3}$ & & $\begin{array}{c}0.0216^{* * *} \\
(0.000)\end{array}$ & $\begin{array}{c}0.0225^{* * *} \\
(0.000)\end{array}$ \\
\hline X4: White & & $\begin{array}{c}0.4228 * * * \\
(0.000)\end{array}$ & $\begin{array}{c}0.4019^{* * * *} \\
(0.000)\end{array}$ \\
\hline X5: Married & & $\begin{array}{c}0.0403^{* *} \\
(0.031)\end{array}$ & $\begin{array}{c}0.0510^{* * *} \\
(0.004)\end{array}$ \\
\hline X6: Medicare & & $\begin{array}{c}0.1209^{* * * *} \\
(0.000)\end{array}$ & $\begin{array}{c}0.0856^{* * *} \\
(0.008)\end{array}$ \\
\hline H6: Dementia & & & $\begin{array}{c}-0.0242 * * * \\
(0.000)\end{array}$ \\
\hline Pseudo $\mathrm{R}^{2}$ & 0.015 & 0.052 & 0.059 \\
\hline Number of Obs. & 25,912 & 25,619 & 25,619 \\
\hline
\end{tabular}

$\dagger$ Significance levels on coefficients: *10\%; **5\%; ***1\%.

$\dagger \dagger$ All equations also include visit numbers 2 to 12 . 
Table 4 shows the importance of including controls when estimating the extent of negligent abuse in NHs. The significant controls were: education, age, being white, married and being eligible for Medicare, which had a positive effect on wearing HAs; and women and dementia symptoms, which had a negative impact. The significance of dementia symptoms makes it important that we downward adjust our foregone benefits estimate of neglect below for this group of non HA users. Without any controls, column (1) reports that NHs reduce HA usage by as much as $41.27 \%$. However, with all the controls, the estimate is still large, though much reduced at $16.72 \%$. We take $16.72 \%$ as the best estimate of the extent of NH negligent abuse. This completes the third test for observing negligent abuse.

\section{SUMMARY AND CONCLUSIONS}

For the deprivation of an activity to be judged a case of neglect, such as the wearing of a $\mathrm{HA}$ in a $\mathrm{NH}$, the behavior must pass three tests. First, the activity must be a basic need, an ADL. The activity must be an essential part of daily living. On its own, the deprivation of an ADL is not a sufficient test of neglect. Satisfying a basic need involves incurring a cost. For example, we referred to the fact that providing a HA over an older person's lifetime costs around \$8,498. Denying a basic need just because of the existence of costs may make no sense because the ADL may generate benefits that exceed the costs. In other words, the ADL may be socially worthwhile. This is the second test for neglect. The benefits must exceed the costs.

The benefits must reflect the preferences of the older adult and thus respect consumer sovereignty. Consumer sovereignty is the foundation stone for modern cost-benefit analysis, which is used by economists to justify any public policy intervention. In the context of older adults, these preferences can be measured in terms of the number of QALYs provided by the intervention. In the case of HA's, the QALYs were found to be worth $\$ 248,425$. The net benefits of HAs were therefore hugely positive and satisfied the second test. Note that on its own, depriving someone of an activity that is socially worthwhile is also not a sufficient test of neglect. A cup of tea or coffee may be highly valued, but it is not necessarily a basic need.

Once an activity has been shown to be both a basic need and one that is socially worthwhile, one can be sure that any deprivation of that activity would be judged neglect if it were to take place. The final test for a judgment of neglect is therefore to provide evidence that deprivation has taken place. For HAs, we found that one-sixth of the non-use of HAs in NHs was deprivation. Some non-use was a preference of older adults. However, at NHs the non-use was significantly higher than the non-use that occurs in residences outside of the $\mathrm{NH}$ system. The deprivation of HAs that took place in NHs passed all three tests required to substantiate the existence of neglect.

One of the ways that neglect differs from the other forms of elder abuse, consisting of psychological, physical and financial abuse, it that it needs to be ongoing. One instance of, say, stealing a wallet or threatening violence is enough to know that elder abuse has taken place. While if a person is prevented from wearing a HA for one day because, say, it needs servicing, that is not necessarily evidence of neglect. In our application of the first test related to HAs, a person was judged to have satisfied the need for a HA if the person "usually" wears one.

This temporal difference between neglect and the other form of elder abuse may help to explain why the monetary valuation of neglect can be so high relative to the other forms of elder abuse. In prior research by Brent (2015), based on data by Brownell (1998), this dealt with elder abuse that was brought to the attention of the criminal justice system. It was therefore not hidden from view like neglect. It was found that financial offenses were valued at $\$ 38,462$ and serious non-financial offenses were valued around $\$ 50,000$. Although these valuations are large, they are much lower than the $\$ 239,927$ loss of net-benefits that was the valuation of HAs that would be the potential benefits if HAs were used. Nonetheless, it must be understood that the financial and serious non-financial cases of elder abuse were for one-time offenses, while the HA case relates to full validated neglect that occurs over the adult person's lifetime.

Using our one-sixth estimate of neglect and the net-benefits value for HAs, we can provide an approximate, national assessment of the scope and value of benefits foregone by elder abuse neglect. McCreedy et al. calculated that there were 1,108,610 long-stay NH residents, 32 percent of which had some HL. This means that there were around 354,755 persons at risk of neglect. Taking one-sixth of this number to be actually validated cases of negligent abuse, this means that the number subject to negligent abuse from the nonprovision of HAs at NHs was 59,244.

To put a monetary value on the number of negligent cases in $\mathrm{NHs}$, we need to adjust the net-benefit estimates in the HA CBA to allow for the fact that residents in NHs have a shorter life expectancy and they are more likely to have dementia. The net-benefits for those without dementia were estimated to be $\$ 239,927$. The life years used in the CBA was 23 for this group. According to Chiu (2019), the life years were 17.9 years in US NHs. Scaling back the net-benefits for this group for the $78 \%$ duration in NHs produces an $\$ 186,726$ figure for this group. For those with dementia, the scaling back has to be much larger. Hicks et al. (2010) found that their sample survived only 1.33 years (the range was 17 to 122 weeks). With a $94 \%$ shorter duration, the net-benefits for the dementia group would have been $\$ 14,396$. Since Gaugler et al. (2018) report that $65 \%$ of the residents in NHs have dementia, a weighted average of the two groups benefits amounts to $\$ 74,708$ per person. Multiplying this monetary sum by the 59,244 persons affected by neglect, results in a $\$ 4.4$ billion projected foregone benefits from HA neglect in NHs in the US. ${ }^{3}$

\footnotetext{
${ }^{3}$ Note that the $\$ 4.4$ billion loss of benefits estimate is a very conservative one. Strictly, when one carries out a CBA, one takes an ex ante perspective. A person investing in HAs gets an expected increased quality of life with and without dementia occurring. It is just that any expected dementia benefits (the indirect benefits) can be added to the expected non-dementia benefits (the direct benefits). It is not one or the other. In the calculation in the text, an ex post perspective is text. That is, in the NH, one knows who has dementia or not. So one can give a lower valuation to any HAs that one newly gives to persons with dementia, relative to any newly given HAs to
} 
Lachs and Berman distinguished serious from less serious categories of elder abuse by neglect. Active neglect is the willful failure of a caregiver to fulfil their care-taking responsibilities, such as provide food or necessary health services. Passive neglect is the non-willful failure to fulfil caregiver responsibilities that could arise, say, from a lack of knowledge about necessary health services. On one hand, there is evidence that the HA neglect we have uncovered in this article may well have been due to a lack of information and so could be classed "passive neglect". Solheim et al. (2016) report that the staff at NHs have insufficient knowledge about hearing HL and HAs. As many as $73 \%$ of informants found that residents needed help with their HAs, but only $10 \%$ of the NH staff reported that they know enough about the residents' HAs. On the other hand, there is evidence in the literature that the HA neglect we have uncovered in this article may well have been willful and so could be classed "active neglect". Solheim et al. also report that $78 \%$ of the NH staff agreed to some extent that more residents would benefit from HAs. Thus, they concluded that HL among the elderly is often ignored by health care workers.

Irrespective of how the neglect is classified, HA deprivation is large, costly and needs to be remedied. It is well known that $\mathrm{HL}$ is greater by those in NHs than elsewhere; see for example, Cohen-Mansfield and Taylor (2004a). This reality implies that HA use should be greater in NHs and not lower as we have found in this article. Greater use can be achieved by providing more HAs in NHs, and/or when they are provided, improving the fit and the functioning of the devices. In the study by Cohen-Mansfield (2004b), 86\% of those with HAs needed help caring for the devices. To achieve greater use of HAs requires greater institutional recognition of the nature and scope of the HL problem by the NHs themselves, see McCreedy et al.

The main research limitation of our study is that we did not have information of the level of HL that a person who is deprived may have. Out measure of HL involved whether a person's hearing was functionally normal or not. If a person's hearing was not functionally normal, we did not know the exact extent to which hearing was below normal. Clearly, HA neglect could be judged to be greater the more one's hearing deviated from the functional norm (say above the normal decibel range of 0 to 20). However, in the CBA of HAs that was used to establish that HAs were socially worthwhile, in the second part of our test of neglect, the benefits of HAs were based on the extent to which they increased the quality of life of its wearers. If the level of HL had been low, the estimated benefits of HAs would not have been found to be so high. In addition, our data set did not have information about the specific characteristics of the $\mathrm{NHs}$ that people lived in. It would have been useful to know, for example, the staffing levels of the NHs, in order that we could ascertain why the volume of neglect that we have uncovered was so high.

persons without dementia. In an ex ante perspective of the loss of netbenefits, everyone (100\%) would get the \$186,726 figure for net-benefits and not just the $35 \%$ in the NHs who turn out not to have dementia.

\section{ACKNOWLEDGEMENT}

The NACC database is funded by NIA/NIH Grant U01 AG016976. NACC data are contributed by the NIA funded ADCs: P30 AG019610 (PI Eric Reiman, MD), P30 AG013846 (PI Neil Kowall, MD), P50 AG008702 (PI Scott Small, MD), P50 AG025688 (PI Allan Levey, MD, PhD), P30 AG010133 (PI Andrew Saykin, PsyD), P50 AG005146 (PI Marilyn Albert, PhD), P50 AG005134 (PI Bradley Hyman, MD, PhD), P50 AG016574 (PI Ronald Petersen, MD, PhD), P50 AG005138 (PI Mary Sano, PhD), P30 AG008051 (PI Steven Ferris, PhD), P30 AG013854 (PI M. Marsel Mesulam, MD), P30 AG008017 (PI Jeffrey Kaye, MD), P30 AG010161 (PI David Bennett, MD), P30 AG010129 (PI Charles DeCarli, MD), P50 AG016573 (PI Frank LaFerla, PhD), P50 AG016570 (PI David Teplow, PhD), P50 AG005131 (PI Douglas Galasko, MD), P50 AG023501 (PI Bruce Miller, MD), P30 AG035982 (PI Russell Swerdlow, MD) , P30 AG028383 (PI Linda Van Eldik, PhD), P30 AG010124 (PI John Trojanowski, MD, PhD), P50 AG005133 (PI Oscar Lopez, MD), P50 AG005142 (PI Helena Chui, MD), P30 AG012300 (PI Roger Rosenberg, MD), P50 AG005136 (PI Thomas Montine, MD, PhD), P50 AG033514 (PI Sanjay Asthana, MD, FRCP), P50 AG005681 (PI John Morris, MD) and P50 AGO047270 (PI Stephen Strittmatter, MD, $\mathrm{PhD}$ ).

\section{CONFLICT OF INTEREST STATEMENT}

The authors declare that they have no conflict of interest.

\section{REFERENCES}

Acierno, R., Hernandez, M.A., Amstadter, A.B. et al.2010. Prevalence and Correlates of

Emotional, Physical, Sexual, and Financial Abuse and Potential Neglect in the United

States: The National Elder Mistreatment Study. America Journal of Public Health, 100,

292-297.

Beekly, D.L., Ramos, E.R., Lee, W.W., et al. 2007 The National Alzheimer's

Coordinating Center (NACC) Database: The Uniform Data Set. Alzheimer Disease

and Associated Disorders, 21: 249-258.

Brent, R.J. 2006. Applied Cost-Benefit Analysis. 2nd ed. Cheltenham, UK: Edward Elgar.

Brent, R.J. 2014. Cost-Benefit Analysis and Health Care Evaluations, 2nd ed. Cheltenham, UK: Edward Elgar.

Brent, R.J. 2015. Valuing the Prevention of Elder Abuse. Applied Economics, 47 , No. $58,6362-6373$.

Brent, R.J. 2017. Advanced Introduction to Cost-Benefit Analysis. Cheltenham, UK: Edward Elgar.

Brent, R.J. 2019. A CBA of Hearing Aids, Including the Benefits of Reducing the Symptoms of Dementia. Applied Economics, 51, 30913103.

Brownell, P. 1998. Family Crimes Against the Elderly: Elder Abuse and the Criminal Justice System. New York: Garland Publishing Inc.

Cohen-Mansfield, J., and Taylor, J. W. 2004a. Hearing Aid Use in Nursing Homes. Part 1: Prevalence Rates of Hearing Impairment and Hearing Aid Use. Journal of the American Medical Directors Association, 5, 283-289

Cohen-Mansfield J. and Taylor J.W . 2004b. Hearing Aid Use in Nursing Homes, Part 2: Barriers to Effective Utilization of Hearing Aids Journal of the American Medical Directors Association, 5, 289296.

Chiu, C-T. 2019. Living Arrangements and Disability-Free Life Expectancy in the United States. PLoS ONE, 14: e0211894. 
Fischer, M.E., K.J. Cruickshanks, T.L. Wiley, B.E.K. Klein, R. Klein, and T.S. Tweed. 2011. Determinant of Hearing Aid Acquisition in Older Adults. American Journal of Public Health, 101, 1449-1455.

Gaugler, J.E., F.Yu, H.W. Davilla, and T. Shippee. 2014. Health Affairs (Millwood), 33, 650-657.

Hicks, K.L., Peter V. Rabins. P.V. and Black. B.S. 2010, "Predictors of Mortality in Nursing Home Residents with Advanced Dementia." American Journal of Alzheimer's Disease \& Other Dementias 25(5): 439-445.

Lachs, M. and Berman, J. 2011. Under the Radar: New York State Elder Abuse Prevalence Study. Final Report. Prepared by: Lifespan of Greater Rochester, Inc., Weill Cornell Medical Center of Cornell University \& New York City Department for the Aging.

Lachs, M. and Pillemer, K.A. 2015. Elder Abuse. The New England Journal of Medicine 373, 1947-1956.

Laumann, E.O., Leisch, S.A. and L.J mWaite. 2008. Elder Mistreatment in the United States: Prevalence Estimates from a Nationally Repre- sentative Study. Journal of Gerontology Series B: Psychological Sciences and Social Sciences 63, S248-254.

McCreedy, E.M., Weinstein, B.E., Chodosh, J. and Blustein, J. 2018. Hearing Loss: Why Does It Matter for Nursing Homes? Journal of the American Medical Directors Association, 19, 323-327.

Morris J.C, Weintraub, S. and H.C.Chui. 2006. The Uniform Data Set (UDS): Clinical and Cognitive Variables and Descriptive Data from Alzheimer Disease Centers. Alzheimer Disease and Associative Disorders, 20: 210-216.

Solheim, J., Shiryaeva, O., and Kvaerner, K.J. 2016. Lack of Ear Care Knowledge in Nursing Homes. Journal of Multidisciplinary Healthcare, 9: 481-488.

Weintraub, S., Salmon. D., Mercaldo, N., et al. 2009 The Alzheimer's Disease Centers' Uniform Data Set (UDS): The Neuropsychological Test Battery. Alzheimer Disease and Associative Disorders 23: 91.

Wooldridge, J.W. 2002. Econometric Analysis of Cross-Section and Panel Data. Cambridge: MIT Press.

Copyright $@$ 2021- All Rights Reserved

This is an open-access article. 